\title{
Improvement of Used Transformer Oils with Activated Bentonite
}

\author{
Loai Nasrat ${ }^{1}$, Mohamed Abdelwahab ${ }^{2}$, Gamal Ismail ${ }^{3}$ \\ ${ }^{1}$ Electric Power \& Machines Department, Faculty of Engineering, South Valley University, Qena, Egypt \\ ${ }^{2}$ Electric Power \& Machines Department, Faculty of Engineering, Minia University, Minya, Egypt \\ ${ }^{3}$ Egyptian Chemical Industries (KIMA), Aswan, Egypt \\ E-mail: loaisaad@yahoo.com \\ Received December 29, 2010; revised April 29, 2011; accepted May 5, 2011
}

\begin{abstract}
This research presents the evaluation of activated Bentonite material for treatment of used transformer oil. Different properties such as; electrical, physical, chemical and thermal of used transformer oil were measured before and after purification and treatment. Two power transformers were used in this research (6.4: 4.6 MVA, 3 phases, $50 \mathrm{~Hz}$ ). One of them was filled with purified oil and the other was filled with activated Bentonite treated oil after purification, and then the two power transformers were tested for one year under practical conditions of the operating field. Initial tests have indicated that the use of Activated BENTONITE in the treatment process for the aged transformer oil improved breakdown voltage, water content, total acidity and flash point. Thus activated Bentonite gives an ideal treatment of aged transformer oil with its environmental and economic advantages. Moreover, activated Bentonite is available at many places in Egypt with low costs.
\end{abstract}

Keywords: Aged Transformer Oil, Bentonite, Breakdown Voltage, Physical and Thermal Properties

\section{Introduction}

Transformer oil plays very important roles in the power transformer as insulation and heat transfer medium, many researches and studies have been reported and examined for decades to understand its electrical, physical and molecular characteristics, behavior under certain condition such as high temperature, techniques to procure the best transformer oils, and so forth [1-3].

Increasing awareness of the environment and the need to limit the impact of human activity gives a clear impetus to replace conventional insulating oils in high voltage plant with environmentally friendly alternatives. In addition, oil leakage from equipment is a serious concern, both in terms of the clear up operation and equipment replacement costs.

The insulation system in transformers can be improved, compared to mineral oil, using new high grade dielectric fluids like Envirotemp FR3 [4-6].

Oil immersed distribution transformers can be built with very low losses compared to dry-type transformers. This fact is well known because oil is a better cooling and insulation medium than air. The active part, core-and winding-design will be smaller in oil, i.e., lower material consumption and lower losses.

Transformer oil acts as a cooling and insulating medium in transformers. This insulating oil not only fills up the pores in the fibrous insulation such as paper, but also the gaps between the turns of the winding and the spacing between the winding and the tank. The oil, in addition to functioning as a dielectric also serves as a cooling medium.

Traditionally, mineral oil, synthetic esters and silicon oils have been used in transformers. More recently, the environmentally friendly sunflower oil has been used as transformer oil for special purposes [7-10].

The life time assessment and evaluation of the condition of a transformer is of high importance for the users and manufacturers. The end of life of the transformer is defined as the decrease in the tensile strength of the isolating paper to approx $50 \%$ of the starting value [11-15].

The insulation system in a power transformer degrades under normal operating conditions, in particular with higher temperature, higher moisture and oxidation. The remnant life of a transformer is significantly influenced by the condition of solid insulation. Currently, degrada- 
tion of insulation in a transformer is monitored by sampling the oil and analyzing for dissolved gases, furan content and by examining the change in the degree of polymerization (DP) of cellulosic paper. In current deregulated electricity markets, non-destructive diagnostic techniques are becoming more and more popular for condition-based maintenance of aged transformers.

In this research tested samples were taken from transformers oils that have been operated 36 years. These transformers were under an annual maintenance and predicated program. Periodical tests have been executed on oil specimens to check properties. Electrical, physical, chemical and thermal properties have been measured according to IEC No. 296 after refining and filtering transformers oils.

The tests results provide that the characteristics of transformers oils after refining process have improved for certain period of time and then the characteristics began to degrade during operating.

Experimental study has been done through this research to evaluate the behavior of transformers oils treated by activated BENTONITE. From the economic aspects, transformers oils are very expensive, so recycling of used transformers oils is very important. Also, recycling used transformers oils give a good solution to avoid environmental pollution.

\section{Experimental Techniques}

\subsection{Transformer Oil Samples}

In this research used transformer oil (under service for 36 years) has been tested. In the Experiments the properties of long period used transformers oils have been measured periodically according to IEC specifications.

The transformer has 6.4: 4.6 MVA, $30 \mathrm{kV} /(511-702)$ V, 90/7700 Amp and 9.3 Ton of oil. The purification process was through purification unit (drying and filtering) with a capacity of 2 Ton/hour under vacuum pressure and temperature $\left(80^{\circ} \mathrm{C}\right)$.

In the treatment process, Bentonite material was used with a certain ratio using heating unit and electric equipment for stirring.

\subsubsection{Bentonite}

The study showed the ability of activated Bentonite material to remove totally all contaminants, ash and carbon contents in treated oil, comparing with untreated oil.

The paper includes actual comparison between normal refining process and activated Bentonite treatment of the same long operating used transformer oil. By operating the oil for the test period of half year and one year, it has been proved that used oil treated with activated Bento- nite gives better results.

\subsection{Methods of Preparation and Acidic Activation for BENTONITE}

1) BENTONITE raw material is grinded softly.

2) Adding concentrated acid to the grinded BENTONITE.

3) Raising the temperature of the mixture up to $70^{\circ} \mathrm{C}$ with continuous stirring for about half an hour.

4) The mixture is left till cooling, and washed through filters for several times till neutralization, and then dried.

5) Regrinding the activated Bentonied material to a fine grade of softness.

\subsection{Advantages of Activation Process}

1) Increasing the surface area of BENTONITE grains to become able of absorption for impurities, suspended matters, and sediment of used transformers oils.

2) Replacing some of cations such as calcium, sodium, and potassium with hydrogen ions in the material lattice structure.

3) Removing the cations of aluminum, iron, and magnesium from lattice structure, which create micro cavities in the material. Thus it increases surface area obviously from the physical aspect and increases the activation from the chemical aspect.

\section{Results and Discussions}

\subsection{Effect of Purification on the Properties of Used Transformer Oil}

Different properties such as; electrical, physical, chemical, and thermal are measured to evaluate the purification process for used transformer oil. The used transformer oil tested before and after purification, and then it was tested after two aging times (half year and one year). A comparison for different properties between four oil samples is shown in Table 1. The four oil tested samples are: used transformer oil (sample U), sample U after purification (sample $\mathrm{P}$ ), sample $\mathrm{P}$ after aging of half year (sample PI), and after aging of one year (sample PII).

It can be noticed from the results of table 1 that, the breakdown voltage is $22 \mathrm{kV}$ for used transformer oil (sample $U$ ) of 36 years service period. While breakdown voltage of sample $\mathrm{P}$ reached to $64 \mathrm{kV}$. For the aging period of half year, the breakdown voltage of sample PI is $57 \mathrm{kV}$. The reduction of breakdown voltage for sample PI is almost $10.9 \%$. While the breakdown voltage of sample PII (one year aging period) is $42 \mathrm{kV}$. The reduction of breakdown voltage for sample PII is almost $34.4 \%$. 
Table 1. Properties of used transformer oil before and after purification.

\begin{tabular}{|c|c|c|c|c|}
\hline $\begin{array}{ll}\text { Property } & \text { Sample } \\
\end{array}$ & $\mathrm{U}$ & $\mathrm{P}$ & PI & PII \\
\hline Breakdown voltage (kV) & 22 & 64 & 57 & 42 \\
\hline Water content (ppm) & 65 & 18 & 28 & 34 \\
\hline Total acidity (mg KOH/g of oil) & 0.2 & 0.08 & 0.09 & 0.11 \\
\hline Ash content \% & 0.1 & Nil & Nil & Nil \\
\hline Carbon content \% & 0.08 & Nil & Nil & Nil \\
\hline Viscosity (Engler) & 1.74 & 1.72 & 1.72 & 1.72 \\
\hline Flash point at $15^{\circ} \mathrm{C}$ & 147 & 148 & 148 & 148 \\
\hline Spec. gravity at $15.5^{\circ} \mathrm{C}\left(\mathrm{g} / \mathrm{cm}^{3}\right)$ & 0.877 & 0.879 & 0.882 & 0.878 \\
\hline Colour & Dark & Dark & Dark & Dark \\
\hline
\end{tabular}

From the results of physical properties, the water content for transformer oil tested samples are 65, 18, 28, and $34 \mathrm{ppm}$ for U, P, PI, PII samples respectively. While the specific gravity values for U, P, PI, PII samples are 0.877 , $0.879,0.882$ and $0.878 \mathrm{~g} / \mathrm{cm}^{3}$ respectively. The viscosity is 1.74 Engler for sample $U$, and it reaches 1.72 Engler for all purified samples. The color of all samples of used transformer oil is dark either before or after purification.

Chemical properties such as total acidity for sample $\mathrm{U}$, P, PI, PII are $0.2,0.08,0.09$ and $0.11 \mathrm{mg} \mathrm{KOH} / \mathrm{g}$ of oil respectively. While ash content is $0.1 \%$ and carbon content is $0.08 \%$ for sample $\mathrm{U}$. But for all purified samples (P, PI, and PII) the ash and carbon content are Nil.

Flash point at $15^{\circ} \mathrm{C}$ as a thermal property is 147 for sample $\mathrm{U}$, while flash point at $15^{\circ} \mathrm{C}$ is 148 for all purified transformer oil samples (P, PI and PII).

\subsection{Treatment with Activated BENTONITE Effect on Different Oil Properties}

After adding an activated BENTONITE material to the purified used transformer oil by using a treatment unit, all oil properties have been measured. Transformer oil after treatment with activated BENTONITE was tested. The treated transformer oil properties were evaluated in two periods of aging (half year and one year). A comparison for electrical, physical, chemical, and thermal properties between used transformer oil before and after treatment is shown in Table 2. Used transformer oil (sample $\mathrm{U}$ ), sample $\mathrm{U}$ after BENTONITE treatment (sample T), sample $\mathrm{T}$ after aging of half year (sample TI), and after aging of one year (sample TII).

The results of Table 2 shows that, sample U has a 22 $\mathrm{kV}$ of breakdown voltage, while the treatment process reaches the value of breakdown voltage up to $68 \mathrm{kV}$ (sample T). The value of breakdown voltage for the sample after aging of half year is $61 \mathrm{kV}$ (sample TI), and is $60 \mathrm{kV}$ for sample TII of one year aging. The reduction of breakdown voltage for samples TI and TII are 10.3\% and $11.8 \%$ respectively.

Physical properties such as; water content for sample $\mathrm{U}$ is $65 \mathrm{ppm}$, while it reaches $14 \mathrm{ppm}$ for all treated samples (T, TI and TII). Viscosity of used transformer oil sample $\mathrm{U}$ is 1.74 Engler, but for all treated samples the value of viscosity is 1.70 Engler. The specific gravity value for all tested samples is $0.877 \mathrm{~g} / \mathrm{cm}^{3}$. The color of sample $\mathrm{U}$ is dark, but it's clear in all treated samples even sample TII of one year aging it's clear and free of suspended matter and sediment.

From the result of chemical properties, total acidity for sample $\mathrm{U}$ is $0.2 \mathrm{mg} \mathrm{KOH} / \mathrm{g}$ of oil, and for sample $\mathrm{T}$ is $0.016 \mathrm{mg} \mathrm{KOH} / \mathrm{g}$ of oil. The total acidity for the aged oil sample for half year (TI) is still $0.016 \mathrm{mg} \mathrm{KOH} / \mathrm{g}$ of oil, but it reaches $0.022 \mathrm{mg} \mathrm{KOH} / \mathrm{g}$ of oil for the sample of one year aging (TII). The ash content of sample $\mathrm{U}$ is $0.1 \%$ and carbon content is $0.08 \%$. But for all treated samples (T, TI and TII) the ash and carbon content are Nil.

The flash point at $15^{\circ} \mathrm{C}$ is 147 for sample $\mathrm{U}$, while flash point at $15^{\circ} \mathrm{C}$ is 148 for all treated transformer oil samples ( $\mathrm{T}$, TI and $\mathrm{TII})$.

\subsection{Comparison between Purification Process and Treatment process for Recycling Oil}

Recycling used transformer oil is a very important process from many aspects. Degradation in all oil properties was found in the used transformer oil of 36 years aging. Also, the properties values were over the limits of IEC no 296. For example; breakdown voltage decreased, 
Table 2. Properties of used transformer oil before and after activated Bentonite treatment.

\begin{tabular}{|c|c|c|c|c|}
\hline Sample & $\mathrm{U}$ & $\mathrm{T}$ & TI & TII \\
\hline Breakdown voltage (kV) & 22 & 68 & 61 & 60 \\
\hline Water content (ppm) & 65 & 14 & 14 & 14 \\
\hline Total acidity (mg KOH/g of oil) & 0.2 & 0.016 & 0.016 & 0.022 \\
\hline Ash content \% & 0.1 & Nil & Nil & Nil \\
\hline Carbon content \% & 0.08 & Nil & Nil & Nil \\
\hline Viscosity (Engler) & 1.74 & 1.70 & 1.70 & 1.70 \\
\hline Flash point at $15^{\circ} \mathrm{C}$ & 147 & 148 & 148 & 148 \\
\hline Spec. gravity at $15.5^{\circ} \mathrm{C}\left(\mathrm{g} / \mathrm{cm}^{3}\right)$ & 0.877 & 0.877 & 0.877 & 0.877 \\
\hline Colour & Dark & Clear & Clear & Clear \\
\hline
\end{tabular}

water content and total acidity, impurities, suspended matter, sediment and carbon content increased, and color changed to dark brown with a smell.

The purification process improved the oil properties for certain values but treatment process with activated BENTONITE highly improved all oil properties values.

\subsubsection{Electrical Properties}

Figure 1 shows a comparison of breakdown voltages between purified oil and BENTONITE treated oil. According to IEC no. 296, breakdown voltage ranged from 30 to $50 \mathrm{kV}$, the purification process improved breakdown voltage of used transformer oil from $22 \mathrm{kV}$ to 64 $\mathrm{kV}$, while adding activated BENTONITE in the treatment process improved breakdown voltage from $22 \mathrm{kV}$ to $68 \mathrm{kV}$. That means that the breakdown voltage has improved in the purification process by almost $190.9 \%$, while it's improved in the Bentioniet treatment process by almost $209.1 \%$.

In Figure 1, it's noticed that after half year of operation, recycled transformer oil breakdown voltage reached $57 \mathrm{kV}$ for sample PI, and $61 \mathrm{kV}$ for sample TI. After one year of operation, recycled transformer oil breakdown voltage reached $42 \mathrm{kV}$ for sample PII, and $60 \mathrm{kV}$ for sample TII. It means that activated BENTONITE increased electrical performance of used transformer oil that the breakdown voltage was improved by almost $7 \%$ in the half year aging sample comparing with the sample of purified oil without using BENTONITE. As for the samples of one year aging, the BENTONITE treated sample was highly improved by almost $42.9 \%$ than the purified sample without using BENTONITE.

Degradation observation of oil properties shows that, after one year of aging the breakdown voltage of transformer oil decreases $15 \mathrm{kV}$ for purified oil, while it de- creases only $1 \mathrm{kV}$ for BENTONITE treated oil.

\subsubsection{Physical Properties}

Physical properties such as; water content (ppm) ranged 13 - 30 ppm according to IEC No. 296 and used transformer oil reached $65 \mathrm{ppm}$. Figure 2 shows a comparison of water content improvement between purified aged transformer oil and activated BENTONITE treated aged transformer oil.

From the result of Figure 2 it can be noticed that, the water content improved after purification of transformer oil, as it reached $18 \mathrm{ppm}$. While using activated Bentonite as a treatment of aged transformer oil (40 years of aging), the water content reached $14 \mathrm{ppm}$. After half year transformer oil operating, water content of purified oil was 28 ppm, it reached 34 ppm after one year. But water content of Bentonite treated transformer oil was still 14 ppm even after one year operating. It may be attributed to ability of activated Bentonite material to absorb moisture from transformer oil.

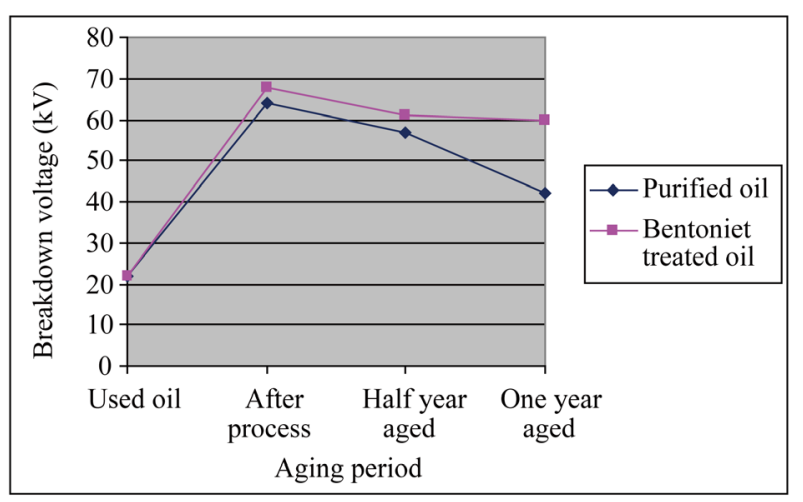

Figure 1. Breakdown voltages of purified oil and BENTONITE treated oil. 


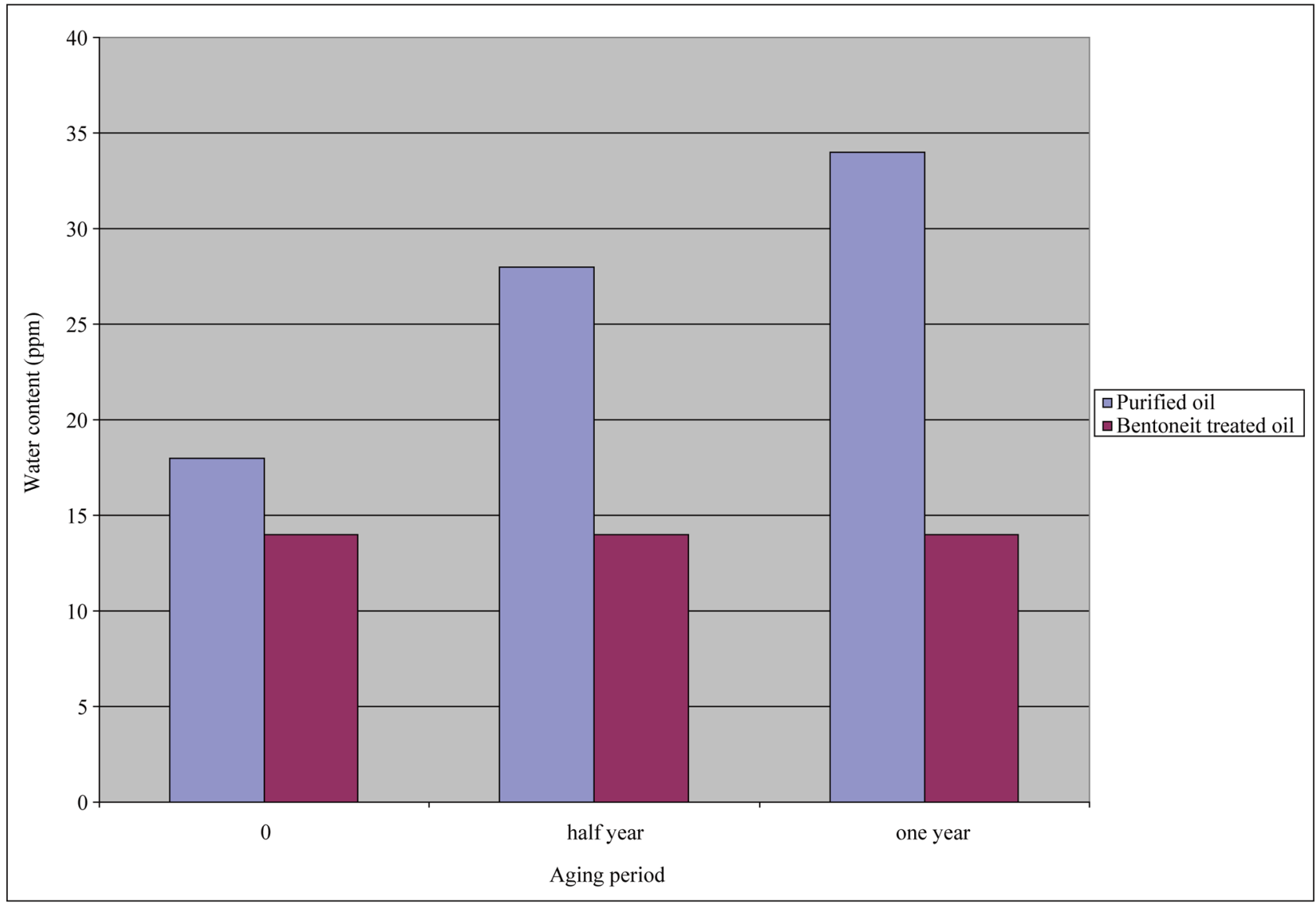

Figure 2. Water content (ppm) for aged transformer oil after purification and activated Bentonite treatment.

Viscosity of used transformer oil was 1.74 Engler. After oil purification, viscosity was 1.72 Engler, and continued to be the same value for even after one year operating. While viscosity value was 1.70 Engler after using Bentonite material and also still reached the same value for even after one year operating.

Specific gravity at $15.5^{\circ} \mathrm{C}$ was $0.877 \mathrm{~g} / \mathrm{cm}^{3}$ for aged transformer oil. It increased to $0.879 \mathrm{~g} / \mathrm{cm}^{3}$ for purified oil, but with using activated Bentonite in treatment of transformer oil it was still $0.877 \mathrm{~g} / \mathrm{cm}^{3}$. After half year of transformer oil operation, specific gravity of purified oil was $0.882 \mathrm{~g} / \mathrm{cm}^{3}$ and it was $0.878 \mathrm{~g} / \mathrm{cm}^{3}$ after one year of operation. In the case of activated BENTONITE treatment, specific gravity was still $0.877 \mathrm{~g} / \mathrm{cm}^{3}$ and didn't change for one year of operation.

The color of used transformer oil is dark even after purification and continuous using for one year. But the color is clear in all Bentonite treated samples even after one year operating, and it's free of suspended matter and sediment.

\subsubsection{Chemical Properties}

According to IEC No. 296, the total acidity is $0.03 \mathrm{mg}$
$\mathrm{KOH} / \mathrm{g}$ of oil maximum. Aged transformer oil either before purification or before treatment has a total acidity of $0.2 \mathrm{mg} \mathrm{KOH} / \mathrm{g}$ of oil, which mean that it is over the IEC limits by almost $85 \%$. But total acidity decreased by almost $60 \%$ for purified oil (0.08 $\mathrm{mg} \mathrm{KOH} / \mathrm{g}$ of oil) and $92 \%$ for BENTONITE treated oil $(0.016 \mathrm{mg} \mathrm{KOH} / \mathrm{g}$ of oil).

After half year of aging, the total acidity of purified transformer oil increased to $0.09 \mathrm{mg} \mathrm{KOH} / \mathrm{g}$ of oil, but it was still the same value of $0.016 \mathrm{mg} \mathrm{KOH} / \mathrm{g}$ of oil for the Bentonite treated transformer oil. After one year of aging, the total acidity of purified transformer oil increased to $0.11 \mathrm{mg} \mathrm{KOH} / \mathrm{g}$ of oil, and $0.022 \mathrm{mg} \mathrm{KOH} / \mathrm{g}$ of oil for the Bentonite treated transformer oil.

Recycling used transformer oil with either purification or Bentonite treatment shows nil of ash and carbon contents even after one year of operating.

\subsubsection{Thermal Property}

Flash point at $15^{\circ} \mathrm{C}$ for used transformer oil was $147^{\circ} \mathrm{C}$; hence, the value according to IEC no. 296 is $154^{\circ} \mathrm{C}$. The flash point value was $148^{\circ} \mathrm{C}$ in either purified or Bentonite treated transformer oil and continued as the same 
value for even after one year operating.

\section{Harmful Environmental Effects of Used Transformers Oils}

1) Used transformers oil is classified as a hazardous waste environmentally, because of its chemical reaction, toxicity, flammability, or ability of explosion.

2) Generally transformers oil is considered heavy metals, non-volatile, and has high molecular weight. When it's spilt in the ground, it spreads easily horizontally and covers a large area separating between the air and the layers of soil.

3) Aged transformers oil contains some toxic chemical resulted of additives to improve oil properties such as heavy metals, organic materials (phenol), and special synthetic transformers oils, which are very toxic, carcinogenic, soluble in water and penetrate in the soil and underground water.

\section{Conclusions}

Work has been done to understand the different properties such as electrical, physical, chemical and thermal of power transformer oil after 36 years in service and then treated with activated Bentoneit. The following conclusions may be drawn:

1) High improvement of breakdown voltage occurs after using activated Bentonite treated transformer oil and reaches $68 \mathrm{kV}$.

2) After one year aging for Bentonite treated transformer oil, some improvements have been achieved. Water content improved 78.5\%, total acidity $89 \%$ and flash point $1^{\circ} \mathrm{C}$.

3) Economically the actual cost for one tone of activated Bentonite treated oil is only $10 \%$ of oil price. Ore material of Bentonite is available at many places in Egypt with low costs.

Environmentally, after activated BENTONITE treatment process for the used transformer oil, activated Bentonite is filtered and can be recycled by re-using it in many applications like wells digging and molding.

\section{References}

[1] H. I. Inyang and L. Kaanagbara, "Estimation of Electric Transformer Service Life from Oil Degradation Kinetics,” Journal of Energy Engineering, Vol. 133, No. 19, 2007, pp. 19-25. doi:10.1061/(ASCE)0733-9402(2007)133:1(19)

[2] T. O. Rouse, "Mineral Insulating Oil in Transformers," IEEE Electrical Insulation Magazine, Vol. 14, No. 3, May-June 1998, pp. 6-16. doi:10.1109/57.675572

[3] B. Garcia, J. C. Burgos, A. M. Alonso and J. Sanz, “A
Moistureoo-in-Oil Model for Power Transformer Monitoring - Part I: Theoretical Foundation,” IEEE Transaction on Power Delivery, Vol. 20, 2005, pp. 1417-1422. doi:10.1109/TPWRD.2004.832366

[4] M. G. Danikas, "Breakdown of Transformer Oil," IEEE Electrical Insulation Magazine, Vol. 6, No. 5, September-October 1990, pp. 27-34. doi:10.1109/57.63080

[5] G. Chen and M. H. Zuber, "Pre-Breakdown Characteristics of Contaminated Power Transformer Oil,” Annual Report - Conference on Electrical Insulation and Dielectric Phenomena (CEIDP 2007), Vancouver, 14-17 October 2007, pp. 659-662.

[6] J. R. Lucas, D. C. Abeysundara, C. Weerakoon, K. B. M. I. Perera, K. C. Obadage and K. A. I. Gunatunga, "Coconut oil Insulated Distribution Transformer," $8^{\text {th }}$ Annual Conference of the IEE, Sri Lanka, 2001.

[7] K. Longva, "Natural Ester Distribution Transformers Improved Reliability and Environmental Safety,” Nordic Insulation Symposium, Trondheim, Norway, 13-15 June 2005.

[8] U. Gafvert, G. Frimpong and J. Fuhr, "Modeling of Dielectric Measurements on Power Transformers," Cigre, Paris, 1998.

[9] Z. T. Yao and T. K. Saha, "Separation of Aging and Moisture Impacts on Transformer Insulation Degradation by Polarization Measurements," Cigre, Paris, 2002.

[10] T. V. Oommen, "Vegetable Oils for Liquid Filled Transformers,” IEEE Electrical Insulation Magazine, Vol. 18, No. 1, January-February 2002, pp. 6-11. doi:10.1109/57.981322

[11] R. Ferguson, A. Lobeiras and J. Sabau, "Suspended Particles in the Liquid Insulation of Power Transformers," IEEE Electrical Insulation Magazine, Vol. 18, No. 4, July-August 2002, pp. 17-23. doi:10.1109/MEI.2002.1019902

[12] R. Blue, D. Uttamchandani and O. Farish, "Infrared Detection of Transformer Insulation Degradation Due to Accelerated Thermal Aging," IEEE Transactions on Dielectrics and Electrical Insulation, Vol. 5, No. 2, April 1998, pp. 165-168. doi:10.1109/94.671924

[13] I. L. Hosier, A. S. Vaughan, S. J. Sutton and F. J. Davis, "Chemical, Physical and Electrical Properties of Aged Dodecylbenzene: Thermal Aging of Mixed Isomers in Air," IEEE Transactions on Dielectrics and Electrical Insulation, Vol. 14, No. 5, 2007, pp. 1113-1124. doi:10.1109/TDEI.2007.4339470

[14] I. L. Hosier, A. S. Vaughan and S. J. Sutton, “Aging Behavior of Dodecylbenzene/Mineral Oil Blends,” Annual Report - Conference on Electrical Insulation and Dielectric Phenomena (CEIDP 2007), Vancouver, 14-17 October 2007, pp. 69-72.

[15] P. Aksamit, D. Zmarzly, T. Boczar and M. Szmechta, "Aging Properties of Fullerene Doped Transformer Oils," Conference Record of the 2010 IEEE International Symposium on Electrical Insulation (ISEI), San Diego, 6-9 June 2010. 